беккроссирования межвидовых гибридов сортами, разное. Образовывались устойчивые, слабовосприимчивые и восприимчивые к болезням формы растений. Это установлено в результате определения гомологичных хромосом между табаком и дикими видами. Гомологичность была малая. Редко встречались гомологичные хромосомы - от 1 пары до 8 пар в единичных клетках при делении в мейозе. Сделан вывод, что в результате хотя и малой конъюгации отмечена транслокация фрагментов хромосом дикого вида в геном табака. Удалось выделить в поколениях «табачных форм» вторых беккроссов линии с разнообразной устойчивостью к болезням. Вторые беккроссы уже служили новым исходным селекционным материалом для создания новых сортов табака, устойчивых в комплексе к основным болезням (табачная мозаика, пероспороз, белая пестрица, черная корневая гниль и др.).

Выявленные закономерности при межвидовой гибридизации в роде Nicotiana на примере применения в межвидовых скрещиваниях N.tabacum материнской формой с дикими видами, показали, что использование механических, физиологических и генетических способов преодоления несовместимостей, при четком проведении контроля процесса мейоза гаметогенеза, можно выделить формы гибридных растений с совершенно новой генетической структурой и высокой устойчивостью к болезням.

1. Научные основы межвидовой гибридизации на плазме Nicotiana tabacum Lin. Краснодар: Просвещение-Юг, 2015. - 189с.

\title{
Отин Г.Ф. \\ Развитие интеллекта через игру с древнейших времен до современности
}

doi 10.18411/scc-30-09-2017-26

idsp 000001:scc-30-09-2017-26

\section{Аннотация}

В статье проанализировано развитие интеллекта через игру, выполняет функцию исследования окружающего мира. В процессе игры происходит освоение внешнего мира, изучение свойств и особенностей самых разных предметов и явлений.

Ключевые слова: моторика, веревочка, орнамент, мультфильм на пальцах, самооценка,развитие интеллекта.

\section{Abstract}

In article is analysed the development of intelligence through a game, performs function of a research of the world around. In the course of the game there is a development of the outside world, studying of properties and features of the most different objects and phenomena,the old manuscripts were examined.

Keywords: motility, string, ornament, the animated film on fingers, a self-assessment, development of intelligence.

Методом развития мелкой моторики детей в древности служила красивая и незаслуженно забытая культураверёвочных фигур, которую знали многие народы дореволюционной России. Именно с российского берега эта культура пошла в другие страны.Шнурок,веревочка,аркан,нитка...

Мелкая моторика - это способность выполнять мелкие и точные движения кистями и пальцами рук и ног в результате скоординированных действий важнейших систем: нервной, мышечной и костной. Относительно моторики кистей и пальцев рук часто применяют термин ловкость. Область мелкой моторики включает большое количество разнообразных движений: от простых жестов (например, захват игрушки) до очень сложных движений (например, писать и рисовать).Развитие мелкой моторики 
играет важную роль для общего развития ребенка. Мелкая моторика развивается уже с новорожденности. Сначала малыш разглядывает свои руки, потом учится ими управлять. Сначала он берет предметы всей ладонью, потом только двумя (большим и указательным) пальчиками. Потом ребенка учат правильно держать ложку, карандаш, кисть. Все мамы знают, что у детей нужно развивать мелкую моторику рук.Происхождение игры неизвестно. Но ведьбыла целая «эпоха веревочного орнамента».Верёвочка, вероятно, возникла как развлекательная игра во многих обществах.Во всём мире существует большое разнообразие подобных игр, в которые играют один или несколько человек. В Великобритании и США игра называется «cat'scradle» (колыбель для кошки), в Германии - «Hexenspiel» (игра ведьмы), на Гавайях — hei (от гав.сетка, сети), на острове Пасха — kaikai, у эскимосов - ajararpoq, индейцев навахо - na-ash-klo (непрерывное плетение), народа макассар из Южного Сулавеси (Индонезия) — toêká-toêká (лестницы, лестница) и конечно у всех коренных народов которые жили в Южной Сибири и на Алтае. Представление об искусстве древних горноалтайцев получится неполным и односторонним.Среди фигур геометрических чаще других древние горноалтайцы пользовались формой круга .Согласно археологической периодизации истории стран Запада, например, период Дзёмонсоответствует мезолиту и неолиту, на Востоке. Дзёмон в буквальном переводе звучит как «эпоха веревочного орнамента».Веревочный орнамент -"мультфильм на пальцах" неизменно вызывает восторг и у детей, и у взрослых, у индейцев Навахо, в Полинезии, на Алтае, у чукчей в России, у эскимосовтакая культура сохранилась до сих пор.Верёвочный курс начался с астрономии индейцев Навахо, потом появились фигуры из Японии и Океании, из Бразилии и Гайаны.Индейцы навахо-последние эмигранты в Америку из Сибири. Многими учеными внимательно изучались самые сложные, асимметричные и подвижные фигуры, которые делали на наших российских арктических побережьях.Культура верёвочных игр существовала не только у них, но и у большинства других народов Сибири. Вот,например игра, которую американские эскимосы называют "Сибирская изба". Она состоит из четырех фигур с сопутствующей историей: люди построили дом и спрятались в нём, но крышу дома ломает медведь, тогда люди ставят шалаш, но медведь опять приходит и всё ломает, тогда люди разбегаются.Цитата из исследования 30-х годов по коренному населению Таймыра из России:"Среди долганских детей на Таймыре,большим успехом пользовалось составление из верёвки на пальцах различных фигур, изображающих сети, спину расшитой женской одежды, ножку куропатки, мережу для ловли рыб и ножницы.",так описывает Попов А.А. другой пример - из исследования игр в традиционном воспитании сургутскиххантов. Здесь цитата о верёвочных фигурах немного больше, но всё равно деталей очень мало:"Ряд интеллектуальных игр ученым удалось записать у сургутскиххантов. Одна из них называлась “Игра с веревочкой”. Играли в нее в любое время года мальчики и девочки. Играли обычно вдвоем. Для игры требовалась веревочка или толстая нитка длиной 1 м. Концы ее связывались и образовывалась петля.Игра заключалась в том, чтобы совместными действиями сплести из веревочки различные фигуры: пилу, кисточки, журавлиные ноги и др.Педагогическое значение игры: игра способствовала развитию сноровки, сообразительности; воспитанию терпения и находчивости.Начали делать подписи к фигурам - Северный Олень, Лиса, Кит, Человек в Каноэ.Позже, в небольшой статье 1933 года об играх северных народов, Владимир Богораз, исследователь, снова упоминает забаву со шнуром на пальцах:"Такая игра, как известно, есть у всех европейских детей, у русских, а также у кафров в Южной Африке. Но чукотско-эскимосские фигуры отличаются большой замысловатостью. «Я долго не мог научиться "снимать" эти фигуры на собственные пальцы, пока не зачертил их на бумаге со всеми подробностями.Общепринятые представления о Севере как о стране мрака, метелей и холода должны быть во многом исправлены ", писал В. Богораз. У него была целая коллекция с инструкциями! Само 
исследование 1904 года в советское время было не очень известно: русская версия книги "Чукчи. Материальная культура" опубликована только в 1991 году.Эти фигуры, а также ещё три десятка верёвочных игр с Чукотки, описаны в замечательном исследовании ДаймондаДженнеса. В 1913 году молодого новозеландского антрополога пригласили в канадскую арктическую экспедицию. 27-летний Д. Дженнес с радостью принял приглашение. После того, как корабль экспедиции раздавили льды, Д.Дженнес три года путешествовал по арктическим побережьям, живя в семьях эскимосов и изучая их обычаи. Могло ли так случиться, что базовые верёвочные игры канадских эскимосов, американских индейцев и даже аборигенов Океании вышли из Сибири? В конце своего отчёта Д. Дженнес приводит ряд наблюдений в пользу именно этой гипотезы.История, как и сама игра - запутанная. Никто точно не знает, когда и где появились эти игры. Их находят у американских индейцев и австралийских аборигенов, у эскимосов, у сибирских коренных народов и африканцев. Если бы Д. Дженнес не был этнологом, он бы наверняка связал "колыбель для кошки" с гораздо более серьезной веревочной системой - узелковым письмом майя, и назвал бы родиной этих игр Центральную Америку. У маори веревочные фигуры до сих пор играют роль "секретного письма", с помощью которого пересказываются древние мифы. Интересна библиотека веревочных игр индейцев Навахо. Все фигуры сопровождаются видеороликами. Кстати, индейцы Навахо считают, что играть в эти игры можно только зимой, когда нечего делать.Дело в том, что почти все упомянутые здесь фигуры, как и "Сибирская изба", являются не одиночной картинкой, а частью последовательности. Это сказки из нескольких фигур, переходящих одна в другую. Например, человек в Каяке плывет к Далёким Горам, а Морж ныряет в Полынью. При этом, как отметил Д. Дженнес, верёвочные сказки из его сибирской коллекции во многих случаях оказались "более полными", чем их аналоги с американской стороны. Например, одна чукотская сказка из пяти фигур с длинным напевом известна на Аляске только с тремя фигурами, а канадские эскимосы в дельте Маккензи знают из всей этой сказки лишь одну картинку, уже без песни,к сожалению.Но для настоящего доказательства этого недостаточно. У западных этнографов очень мало сибирских фигур. Поэтому они могут сказать, что многие веревочные фигуры распространялись по Америке со стороны Берингова пролива.У канадских индейцев Квакиютль тоже была аналогичная фигура, Лягушка. И тоже не похожая на лягушку, если судить по современным описаниям.Д. Дженнес пишет, что сибиряки делали эту фигуру вдвоём, однако сам он научился делать в одиночку. Видимо, в этом и проблема: технически всё верно, но результат не похож на название.Остаётся добавить, что верёвочная культура индейцев Квакиютль стала известна миру благодаря другому выдающемуся русскому этнографу, Юлии Аверкиевой. В 1930 году американский антрополог Франц Боас отправился в экспедицию на остров Ванкувер и пригласил с собой 23-летнюю выпускницу географического факультета Ленинградского Государственного Университета, Юлию Аверкину, которая попала в США по программе студенческого обмена. Ф. Боас поручил ей собрать информацию о веревочных играх индейцев. Отчет Аверкиевой объемом почти 400 страниц содержал детальное описание более 100 фигур - это самая объемная коллекция веревочных игр, собранных у одного племени. Кроме того, в ее исследовании описываются индейские обряды, которые были официально запрещены в Канаде (потлач).История, как и сама игра - запутанная.

Никто точно не знает, когда и где появились эти игры. В 1960 году наследники Боаса передали рукопись Ю.Аверкиевой в Музей естественной истории,а биохимик Марк Шерман, изучавший веревочные игры,издал её в 1992 году в США, под названием KwakiutlStringFigures. При этом Шерман не ограничился инструкциями индейских фигур: он добавил сравнение с фигурами эскимосов и чукчей, а также интересные размышления о том, как верёвочные игры могут подтвердить или опровергнуть существующие ныне теории происхождения северных народов и 
заселения Америки. И тут же в очередной раз отмечено, что более серьёзная коллекция верёвочных игр из Сибири очень помогла бы в этих исследованиях.Самобытный звериный стиль существовал и у древних пермских народов... началоРодановской культуры (9 - 15 вв.).Забава детской игры, в которую довелось поиграть с пермяками, это обрамление большинства предметов пермского звериного стиля веревочным контуром.Настоящие представители древней прото-угорской культуры это современные народы уральской расы.Культура древних племен Приуралья и Западной Сибири,заметную роль в политической жизни Кангюя на протяжении ряда веков играв гребенчатой (или штампованно-веревочной)культуре. Тем временем журнал WallStreetJournal на международном уровне поддержал идею о том, что эти игры отлично развивают мозги.
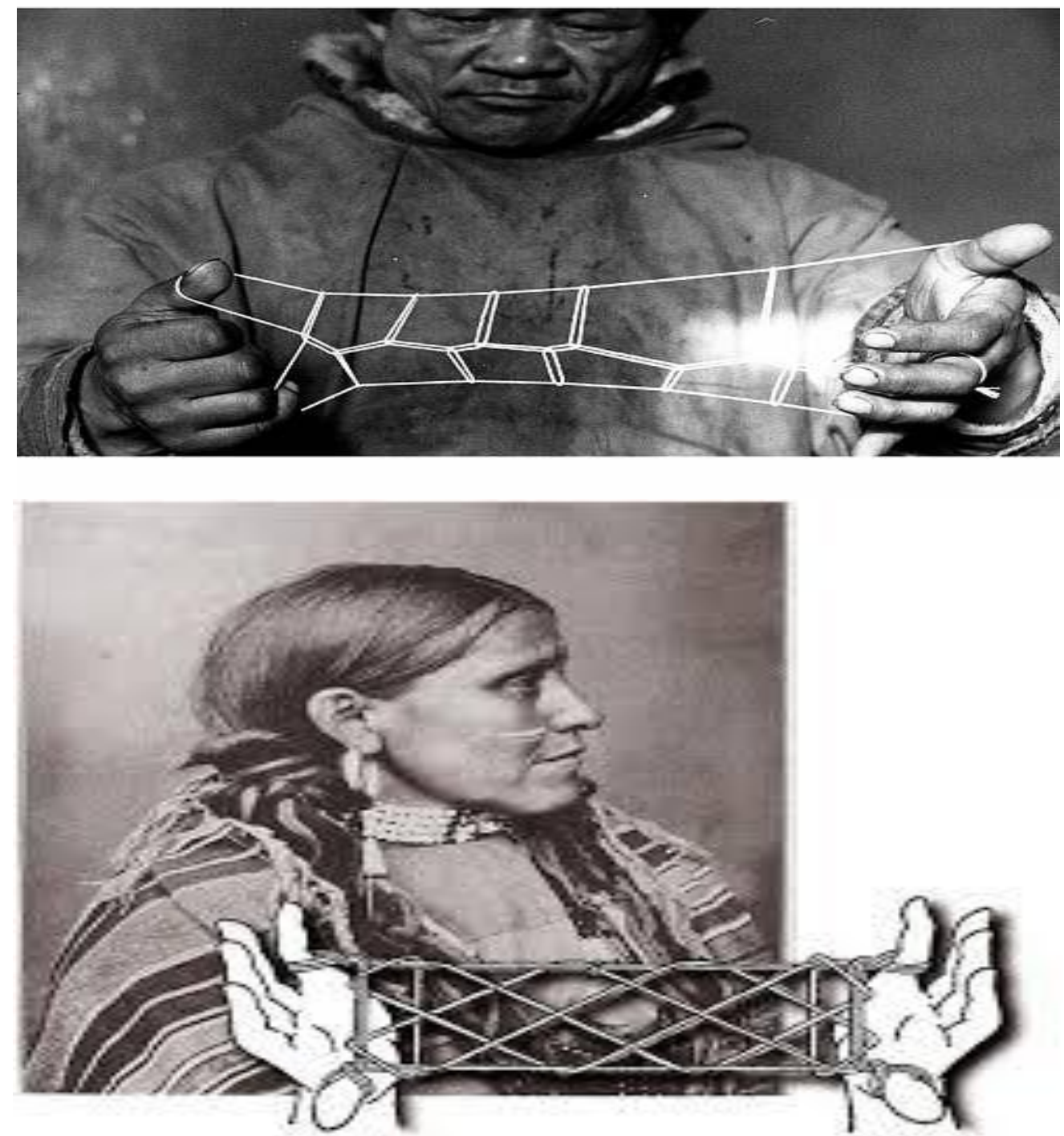

Поиски прошлого -это не только путешествие во времени.

Путешествия во времени-это уникальная возможность оценить, развитие интеллектуальных способностей и возможностей наших предков придуманного, со временем усовершенствованного. Наши предки делились своими играми друг с другом, представлениями о разных пониманиях и верованиях. Мне бы хотелось познакомить вас с кетоязычными народами.По представлениям кетоязычных народов, они проживали на большой территории от Восточного Казахстана(реки Иртыш),до Саяно-Алтая и до Енисея весь мир делился на «верх» и «низ», его «каменную» и «войлочную» стороны. На севере, в устье Енисея, к которому, кстати сказать, не могло быть применено кетское слово «сес» - «река»,- он был особым объектом,- так вот, в 
устье Енисея небо сходилось с Землей и там обитал злой дух Хосядэм,. На юге, у истоков Енисея, небо тоже сходилось с Землей, и там обитала «мать жизни», Томэм.Кетоязычныеарины, пумпоколы, байкотовцызнали о том, что есть множество таких же рек, как Енисей, что вокруг раскинулся бескрайний мир, что за тайгой лежит огромная земля. Сейчас проживают только кеты на Енисее, остальные кетоязычные народы остались только в истории и смешались с другими народами. Само слово «кет» означает «человек».Сохранилась от древних времен одна удивительная игра, очень похожая на наши шашки в которую играли кетоязычныеарины в 18-19 веках. Но борьбу ведут не «белые» и «черные», а фигурки женщин и мужчин. Почти точно такие же шашки были найдены за тысячи километров от Енисея,- при раскопках таинственного города древней Индии Мохенджо-Даро. Случайное совпадение? Или же правы те ученые, которые утверждают, что кетоговорящие народы - последние остатки создателей культуры Мохенджо-Даро, которые в течение многих веков вытеснялись с юга на север и прошли путь от жаркой Индии до таежной Сибири? Необычная одежда кетов-это халат с запахом у женщин, сильно отличает их от других народов. Когда-нибудь наука решит эту загадку. Но шашечные фигурки кетоговорящих народов интересны не только своим родством с шашками древнейшего города Индии. Ведь война «мужчин» и «женщин» - это отражение той борьбы, которая в незапамятные времена шла между мужчинами и женщинами за право господства в обществе, борьбы матриархата и патриархата! И как знать, может быть, началась она именно со счета дней. В состав Московского государства кеты вошли в 1607 году." Сибирско-Алтайские шашки оказались этническим эндемиком,те народные игры в большей степени выполняют культовую функцию, олицетворяют связь с предками и в сущности играют роль исторического наследия, а не спортивной дисциплины. Такая игра - неотьемлемая часть праздничного гулянья вкупе с состязаниями борцов и бегунов, стрельбой из лука, песнями, плясками и поеданием вкусностей.В древних игровых наборах не всегда были именно доски: большой плоский кусок дерева малопригоден для кочевой жизни. В восточной традиции их чаще делали матерчатыми или войлочными. Большинство «досок» монгольского шатара были нарисованы или выжжены на кошме (в Бурятии и Туве и сегодня так делают).Область Горного Алтая повидала немало народов - от неустановленных древних ариев, «строителей степных пирамид» саков (скифов), до гуннов, монголов, тюрков и китайцев. История их переселений туманна.Однако прото-шашки (петтея, латрункули) намного старше шахмат, у них было время проникнуть в самые отдалённые уголки древнего мира, развивая интеллект.Непременный спутник детства и важнейший инструмент игры игрушка.Взрослого тоже привлекают игрушки, но характер интереса взрослого и ребенка к игрушке качественно различны.Особенно привлекательны для ребенка игры, в которых активно используется его стремление к новизне Новые, случайно обнаруженные эффекты увлекают, вызывают интерес.В наши дни,необходимость тренировки ментальных функций мозга, отвечающих за получение, обработку и хранение информации приводит к росту популярности интернет-ресурсов, предлагающих on-line-games по развитию мыслительных способностей.Мы живем в эпоху смены научной парадигмы. Специалисты в области когнитивных наук, психологи, врачи, педагоги и другие профессионалы, чья работа в той или иной степени касается психики или нервной системы, жили с представлением о том, что человеческий мозг совершенствуется лишь на первых этапах развития и, достигнув пика развития в юности, начинает постепенно и безвозвратно увядать.С каждым годом подобных исследований становилось все больше, их условно объединили под теорией пластичности мозга. По словам профессора Санкт-Петербургского Государственного УниверситетаТатьяны Черниговской - одного из ведущих отечественных исследователей в области когнитивных наук: « Пластичность позволяет нам говорить о возможности развития мозга и когнитивных функций не только детей, но и взрослых. 
Есть лишь один нюанс: пластичность мозга тем меньше, чем меньше вы его тренируете. Мозг должен всегда работать, и развивается он лишь тогда, когда ему дается сложная задача.Чтобы развивающие игры работали, они должны усложняться по мере продвижения игрока и давать ему обратную связь». Поэтому в идеале разработчик такой игры должен сначала провести исследование, которое подтверждало бы, что эта игра развивает когнитивные функции - и развивает именно те функции, для которых она была разработана (все вместе это называется «валидность»). Для этого требуется провести эксперимент - необходимо заставить фокус-группу в течение месяца играть в игру.Современные проекты on-line, направленный на развитие человека, призванный помочь людям стать хотя бы немного лучше, изменить себя и изменить свою жизнь в лучшую сторону.

$$
* * *
$$

1. Александр Нефёдкин, "Военное дело чукчей" - СПб.: Петербургское востоковедение, 2003

2. Попов А.А, "Семейная жизнь у долган". - Советская этнография, 1946.

3. В.П.Красильников, «Игры и состязания в традиционном физическом воспитании хантов». Екатеринбург: Изд-во РГППУ, 2002

4. The Chukchee. Material Culture by W. Bogoras. - Memoirs of the American Museum of Natural History ; v. 11. Leiden, E.J. Brillltd, 1904

5. В. Г. Богораз. "Игры малых народностей Севера". - Сборник Музея антропологии и этнографии. Изд-воАНСССР, 1949.

6. Eskimo String Figures By D. Jenness - Report of the Canadian Arctic Expedition 1913-1918. Volume XIII, 1924

7. Аверкиева Ю.П. Из экспедиционных материалов по индейцам квакиютль. - Аборигены Америки: предметы и представления. Санкт-Петербург: РИОМАЭРАН, 2005.

8. Kwakiutl String Figures by Julia Averkieva and Mark A. Sherman - Anthropological papers of the American Museum of Natural History: v. 71, 1992

9. Mary-Rousseliere, G. "Les Jeux deFicelle des Arviligjuarmiut" - MuseesNationaux du Canada Bulletin 233, 1969.

10. Шур Я.И. Когда? Рассказы о календаре. 